\title{
The Optimization of EDX Performance in Tecnai TEMs
}

\author{
H.S. von Harrach*, B. Freitag*, W.Gerits*, E. van Cappellen* and A. Sandborg** \\ *FEI Electron Optics, P.O. Box 218, 5600KE Eindhoven, The Netherlands \\ **Edax Inc, 91 McKee Drive, Mahwah, NJ 07430 USA
}

It is well known that the ability to detect small amounts of an element in a specimen by $\mathrm{X}$-ray microanalysis [1], the minimum mass fraction, is determined largely by the count rate and the peak-to-background ratio $(\mathrm{P} / \mathrm{B})$ in a spectrum. It has long been a criticism [2] of standard $200 \mathrm{kV}$ and $300 \mathrm{kV}$ TEMs that low $\mathrm{P} / \mathrm{B}$ ratios and spurious peaks limit the analytical performance of these instruments. Recent work on the FEI Tecnai 200kV and $300 \mathrm{kV}$ FEG SuperTwin instruments $(0.14 \mathrm{~nm}$ lattice and $0.2 \mathrm{~nm}$ STEM resolution at $200 \mathrm{kV}$ ) with Edax X-ray detectors has been carried out to optimize the EDX performance.

As reported previously [3], the use of a light material, such as beryllium, to cover surfaces exposed to electrons scattered from the specimen can reduce the presence of spurious peaks and raise the $\mathrm{P} / \mathrm{B}$ ratio in the spectrum. Fig. 1 shows a spectrum of a standard $\mathrm{NiOx}$ specimen on a molybdenum grid obtained under typical analytical conditions at $200 \mathrm{kV}$, using a low-background double-tilt specimen holder at zero degrees of tilt and Be shields above and below the specimen. The spectrum shows a P/B10 ratio (Fiori number [4]) of about 3500. In addition to the expected nickel and oxygen peaks from the sample there is a small molybdenum peak which originates from the support grid, and small Fe and Co peaks from the surrounding materials. These spurious peaks are at most $0.5 \%$ of the $\mathrm{NiK}_{\alpha}$ peak, and are reduced as the specimen is tilted towards the detector.

The use of Be shields reduces the tilt range available for the specimen holder. For this reason another solution was sought. From a theoretical point of view [1], the P/B ratio is increased by raising the take-off angle of the detector. A redesign of the collimator made it possible to raise the take-off angle to $20^{\circ}$ without significantly decreasing the solid angle of collection $(0.13 \mathrm{srad})$. The result was a dramatic increase in $\mathrm{P} / \mathrm{B} 10$ ratio to $>4500$ at $200 \mathrm{kV}$ (Fig.2) and to $>5000$ at $300 \mathrm{kV}$ under the same conditions as above. Furthermore, there was a reduction in the level of spurious peaks to less than $0.2 \%$ relative to $\mathrm{NiK}_{\alpha}$ at both acceleration voltages.

The data are summarized in Table 1, where the $\mathrm{P} / \mathrm{B} 10$ ratios and percentages of spurious peaks are listed for the two detector configurations. It shows the enormous advantage of the higher take-off angle with the new design. The Be shields give lower $\mathrm{P} / \mathrm{B}$ ratios and have the practical disadvantage of limiting the specimen tilt range to about $15^{\circ}$, compared to $30^{\circ}$ without the shields. The high take-off geometry without Be shields is likely to be the optimum solution for most applications.

\section{References}

[1] J.I. Goldstein et al., in Principles of Analytical Electron Microscopy (ed. D.C. Joy et

al.) Plenum, New York, 1986

[2] W.A.P. Nicholson et al., J. Microsc. 125 (1982) 25 
[3] C.E.Lyman et al., J. Microsc. 176 (1994) 85

[4] C. Fiori et al. Microbeam Analysis-1982 (1982) 55

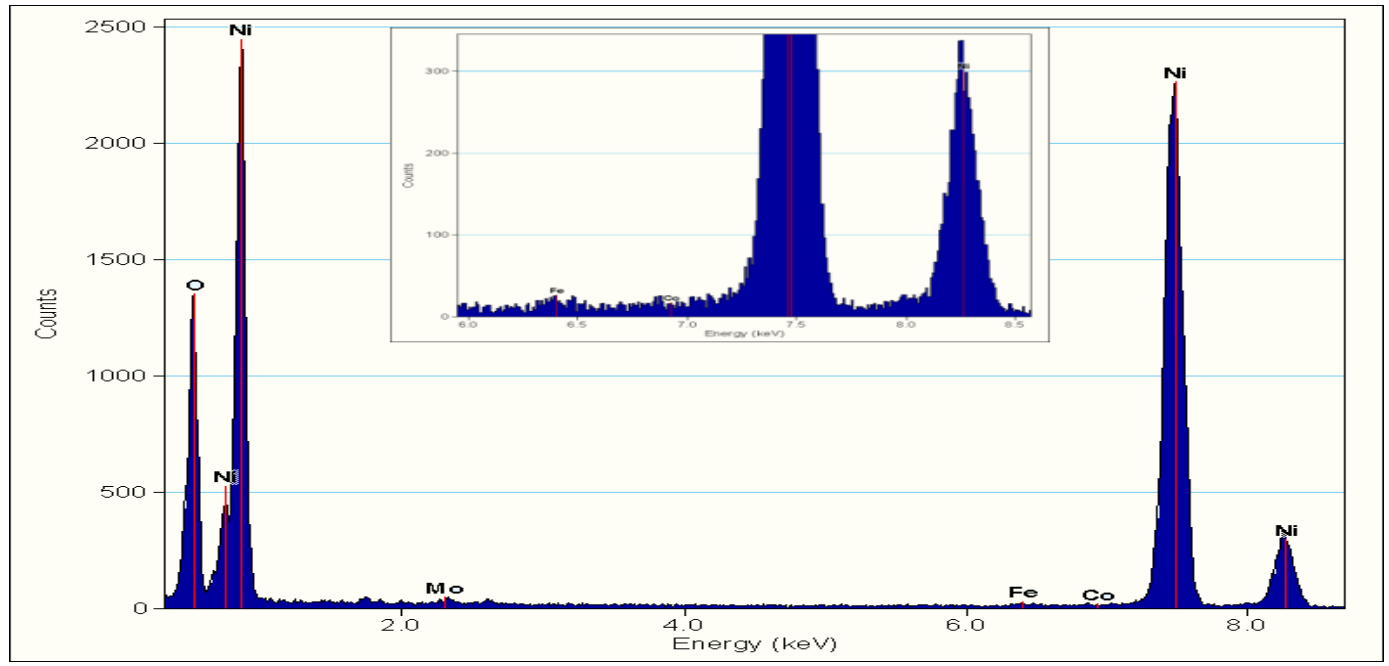

Fig.1 NiOx spectrum with Be shields, $200 \mathrm{kV}, 0^{\circ}$ tilt angle (insert: enlarged view at 6-8.5 keV)

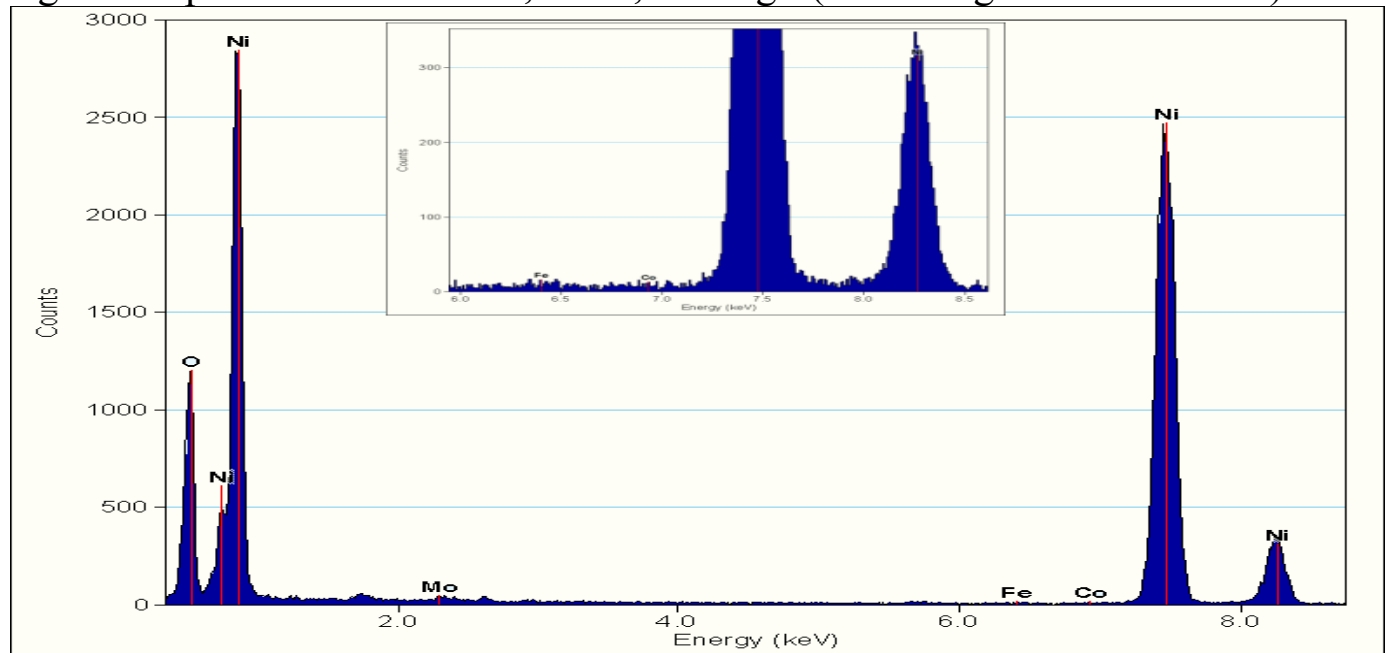

Fig. $2 \mathrm{NiOx}$ spectrum with new collimator, $20^{\circ}$ take-off, $200 \mathrm{kV}, 0^{\circ}$ tilt angle (insert: enlarged view at $6-8.5 \mathrm{keV}$ )

TABLE 1 Summary of measurements at 200 and $300 \mathrm{kV}$, Tecnai F20 and F30 SuperTwin

\begin{tabular}{|l|l|l|l|l|}
\hline Detector geometry & kV & $\begin{array}{l}\text { Fiori number } \\
\text { P/B10 }\end{array}$ & $\begin{array}{l}\text { Spurious } \\
\text { peaks } \\
\text { \% Fe/NiK }\end{array}$ & $\begin{array}{l}\text { Specimen tilt } \\
\text { range }\end{array}$ \\
\hline Be shields, $15^{\circ}$ take-off, $0^{\circ}$ tilt & 200 & 3460 & 0.49 & $\pm 15^{\circ}$ \\
\hline Be shields, $15^{\circ}$ take-off, $15^{\circ}$ tilt & 200 & 4130 & 0.39 & $\pm 15^{\circ}$ \\
\hline $20^{\circ}$ take-off, 0.13 srad, $0^{\circ}$ tilt & 200 & 4680 & 0.17 & $\pm 30^{\circ}$ \\
\hline $20^{\circ}$ take-off, 0.13 srad, $15^{\circ}$ tilt & 300 & 5160 & 0.17 & \\
\hline & 200 & 4710 & $\varangle 0.1$ & $\pm 30^{\circ}$ \\
\hline
\end{tabular}

